\title{
A CRITICAL TAXONOMY OF SOCIO-ECONOMIC STUDIES AROUND BIOMASS AND BIO-WASTE TO ENERGY PROJECTS
}

\section{Gratitude Charis *, Gwiranai Danha and Edison Muzenda}

Botswana International University of Science and Technology - Chemical, Materials and Metallurgical Engineering, Private bag 16, Palapye, Botswana

Article Info:

Received:

24 March 2018

Revised:

18 June 2018

Accepted:

18 July 2018

Available online:

1 August 2018

Keywords:

Biomass

Residues

Viability

Impact

Socio-economic

\section{ABSTRACT}

Since biomass and bio-waste to energy systems condense activities that have important socio-economic and environmental sustainability effects, it is important that viability and impact studies have a socio-economic dimension, beyond the techno-economic and institutional aspects. This is necessitated in particular, by the limited and scattered availability of biomass or its residues, links to agricultural and forestry activities and associated socio-economic sustainability issues like land use, harvesting, transporting and economic conversion plant supplies. Such socio-economic studies, done prior to the project, can reflect a lot on the feasibility of projects, likely impacts and even help to optimize facility locations, network configurations or fleet management at various points or on the whole the supply chain. When the studies are done in retrospect of the project, as impact studies, they show how bioenergy projects can transform societies. The impact studies can then be useful precursors to similar projects within the same country/region or other similar regions. This review classifies socio-economic study literature into 'viability' studies- done prior to the project; and 'impact' studies- usually done after the project, except for 'projected impact studies'. The studies are also classified as 'quantitative and systematic' or 'qualitative'. Nonetheless, there are occasional overlaps between these study classes. Intentionally designed integrated approaches could actually give more comprehensive results, although in most cases, they result in complex models. This classification can guide researchers to make the right choice of the socio-economic study to carry out based on their objectives.

\section{INTRODUCTION}

The need for comprehensive socio-economic studies around bioenergy projects has been emphasized by different authors for various reasons (Deenanath, lyuke, \& Rumbold, 2012; Gasparatos et al., 2015; Ji \& Long, 2016; Nogueira, Antonio de Souza, Cortez, \& Leal, 2017; Pradhan \& Mbohwa, 2014). Bioenergy projects in this study are inclined towards 2nd generation (2G) biofuel production from biomass and its residues or waste, although some cases of $1 \mathrm{st}$ generation studies and conversions to heat or power will be used occasionally as examples. Socio-economic studies around such projects can serve different purposes, depending on their focus. For instance countrywide surveys help to quantify and contextualise biomass distributions in various regions, while feasibility studies have been carried out to assess the potential viability of setting up a particular project in specific regions, taking socio-economic and ecological factors into consideration (lakovou, Karagiannidis, Vlachos, Toka, \& Malamakis, 2010).
Socio-economic impact studies, on the other hand, help to quantify the socio-economic effect of bioenergy projects; and such case studies can serve as precursors of similar projects within the same region or in parallel regions (Pradhan \& Mbohwa, 2014). The importance of prior socio-economic surveys has been demonstrated by the results of the Jatropha hype in Africa. More than $40 \%$ of the projects failed because that were started on the premises of projected assumptions, with no proper validation through socio-economic studies (Gasparatos et al., 2015). The studies could have exposed the plant's actual climatic, soil, water and labour requirements; the willingness and ability of communities to meet the demand; potential competition with agricultural inputs and/or infrastructure and sustainability of the supplies (Econergy, 2008).

Such socio-economic studies are pertinent and relevant because bioenergy projects represent a convergence of many socio-economic activities. In their analysis of socio-economic studies on biofuels, especially in the developing world, Nogueira et al. (2017) noted that bioenergy 
systems are strongly linked to activities with important socio-economic and environmental sustainability effects (Nogueira et al., 2017). This is because they lie at the intersection of energy and agricultural/forestry activities. In light of this, socio-economic viability or impact analyses of bioenergy systems are vital and should also include 'agricultural, environmental, economic and social aspects in addition to technological and institutional factors' (Nogueira et al., 2017).

An analysis of the mix of factors that will determine the biomass and therefore, bioenergy potential of a country or region (Figure 1), shows that more than $70 \%$ of these factors are socio-economic; spanning land, agriculture, logistics, policies, skilled labor availability and demographics (Gasparatos et al., 2015), (Von Maltitz \& Setzkorn, 2013), (Econergy, 2008), (Friends of the earth, 2009). Inevitably, the success of a biofuel project for instance will, to a large extent, depend on these socio-economic factors, assuming technical and commercial viability. Already, the large demand for biofuels globally makes for a strong case for commercial viability (Econergy, 2008). Therefore, beyond technical R\&D, site specific studies of regions with a high potential for biofuel projects should also be made to assess the biofuel potential, given the external socio-economic constraints (lakovou et al., 2010).

To date, most research has focused on the techno-economic feasibility of producing biofuels like ethanol through various routes, but not much has been done on socio-economic side; especially in creating universal and/or integrated models and solutions (Nogueira et al., 2017). For instance, Pradhan and Mbohwa (2014) assert that comprehensive studies will be required to identify suitable feed stocks and technologies to establish a successful biofuel industry in South Africa (Pradhan \& Mbohwa, 2014). Studies like feasibility assessments and supply chain optimizations can help assess and ascertain viability of such bioenergy projects, while impact studies like Life Cycle Analysis (LCA) can help evaluate socio-economic and environmen-

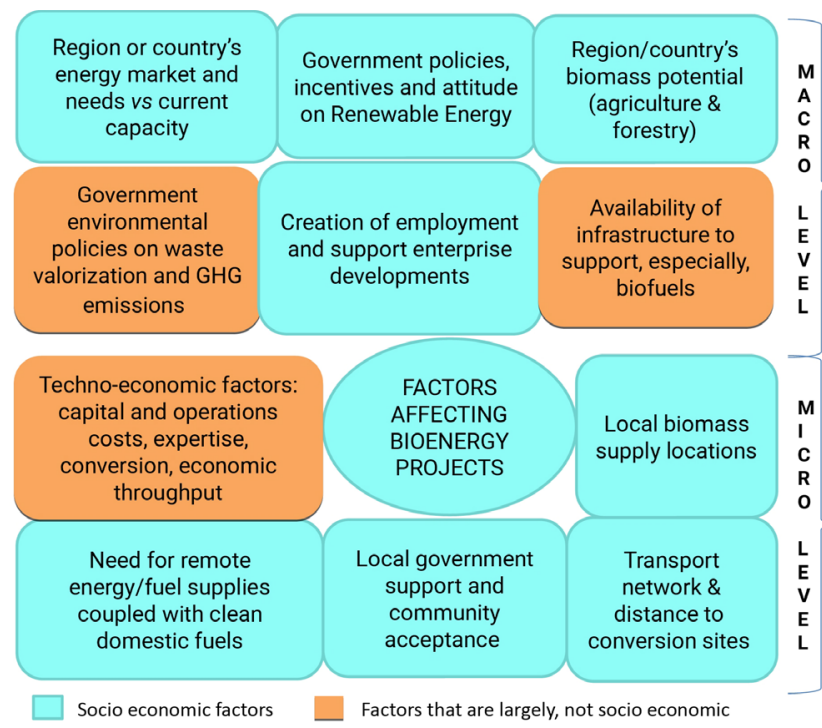

FIGURE 1: Factors that affect bioenergy projects. tal impacts through projections or in retrospect. Integrated socio-economic studies that cover the whole supply chain and use a combination of approaches, with various combinations of feed stocks and technologies, would be ideal, although they are complex to build. Pradhan and Mbohwa (2014) asserted that localized LCA studies could therefore help select the right feedstock and technologies best suited to the nation(s) and advise policy makers accordingly (Pradhan \& Mbohwa, 2014).

\section{TAXONOMY AND NOMENCLATURE: VIA- BILITY CONSIDERATIONS AND IMPACTS}

This section reviews literature on socio-economic studies done prior to biofuel projects (viability considerations, including projected impact studies) and retrospective to biofuel projects as summarized in Figure 2. In most cases, these studies exclude detailed techno-economic study of the conversion plant, but span the upstream supply chain, value chain and impacts on relevant stakeholders.

The socio-economic studies will be further classified as follows:

- Quantitative and systematic socio-economic studies: incorporating computational (mathematical or heuristic) models to measure certain results, potential outcomes or compare methods or routes ( $\mathrm{Ba}$, Prins, \& Prodhon, 2016). The basis for conclusions and recommendations is evidence from systematically drawn facts, though accuracy depends on the reliability of the model and its inherent assumptions. Examples are supply chain optimization through use of mathematical, heuristic or simulation models. In retrospective studies, some quantitative and systematic models have also been used to evaluate projects, for instance Lifecycle Assessments (LCA). Such models can be used to project impacts for other similar projects and provide insight for decision making (Nogueira et al., 2017).

- Qualitative socio-economic studies: These studies are usually surveys made, especially to assess the impact of projects in retrospect. When done prior to the project, they usually address subjective issues like communities' readiness to embrace a biofuels venture. These studies are more relevant when done in retrospect, since they are based on historical facts and evidence, including statistical facts. Since statistics are used in a pure historical rather than modeling context in this case, they do not then qualify such literature as 'quantitative and systematic, according to this discussion.

As previously discussed, a number of authors have stressed on the importance of conducting socio-economic studies, especially prior to launching a biofuel project (Amundson, Sukumara, Seay, \& Badurdeen, 2015; Batidzirai, Smeets, \& Faaij, 2012; Friends of the earth, 2009; Gasparatos et al., 2015); although retrospective impact studies are also important in informing future policies for the same or other regions (Pradhan \& Mbohwa, 2014). 


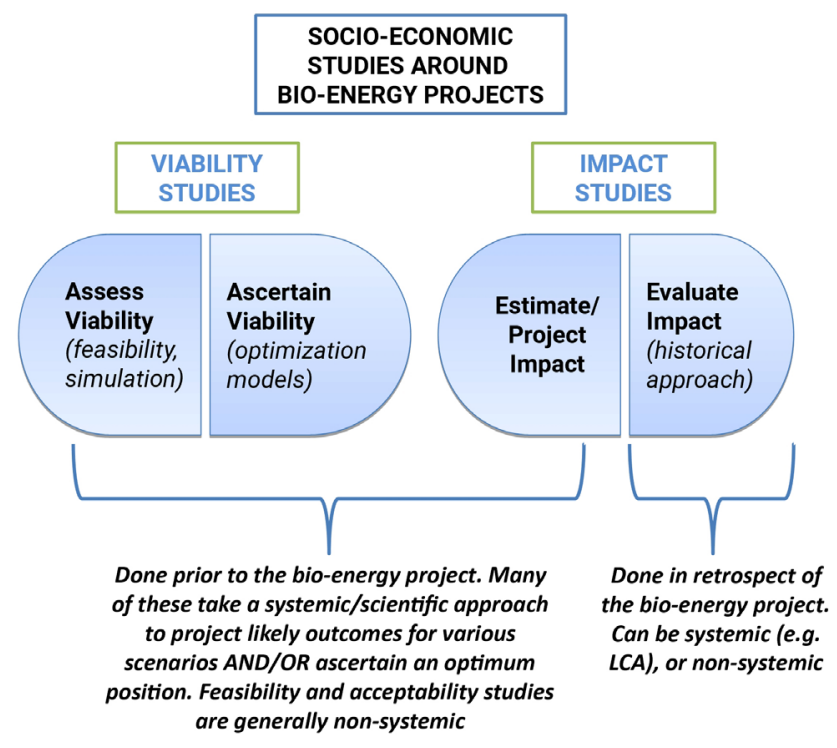

FIGURE 2: Classification of socio-economic studies around bio-energy projects.

\section{SOCIO-ECONOMIC VIABILITY STUDIES}

\subsection{The distinction between 'techno-economic' and 'socio-economic' studies}

A survey of literature shows a distinction between techno-economic and socio-economic studies around biofuels (Patel, Zhang, \& Kumar, 2016; Timilsina \& Shrestha, 2010). Techno-economic studies are mostly connected with the plant design/flow sheet (otherwise referred to as 'plant economics'), while socio-economic studies largely look at the flows of energy from the environment (societies) into or out of the plant and sustainability or impact of such flows (Badger, Badger, Puettmann, Steele, \& Cooper, 2011; Dassanayake \& Kumar, 2012; Patel et al., 2016). As discussed later, they are also integrated socio-economic studies that include detailed techno-economic schemes in the supply chain study, although these can be complex.

\subsection{Socio-economic viability studies}

Most reviewed literature that looks at the viability considerations for biofuel ventures has taken a quantitative and systematic approach. This is largely true for simulations and optimizations; while some feasibility assessments and acceptability surveys are mostly statistical. As depicted in Figure 2 socio economic viability studies have been classified in this study into those that assess viability or sustainability of a venture (viability assessments) AND those that aim at ascertaining viability through optimization.

\subsubsection{Assessing viability}

Noguiera et al. (2017) conduct a concise review of socio-economic studies made to assess and evaluate the sustainability of biofuel projects (Nogueira et al., 2017). The following models (Table 1), in their study, can be done prior to the launch of the project, as viability assessments.

Musango et al. (2011 \& 2012) suggested the use of SD in assessing the sustainability of various conversion technologies in the African context if some renewable energy policies are enacted. They demonstrate an SD simulation approach through the Bioenergy Technology Sustainability Assessment (BIOTSA) model (Musango et al., 2012, 2011). Barisa et al. (2015) also used SD approach and looked into prospective biodiesel policy interventions and consumption patterns and their impact on ecosystem dynamics and services in Latvia (Barisa et al., 2015). Martine-Hernandez

TABLE 1: Types of viability assessments.

\begin{tabular}{|c|c|c|c|}
\hline Study model & Description & Strengths and weaknesses & Literature \\
\hline $\begin{array}{l}\text { Simulation models e.g. } \\
\text { System Dynamics (SD), } \\
\text { Agent Based Modelling } \\
\text { (ABM), Monte Carlo } \\
\text { Simulation } \\
\text { Quantitative and } \\
\text { systematic approach }\end{array}$ & $\begin{array}{l}\text { This is a well-established approach in many fields, } \\
\text { that uses properly understood interrelationships } \\
\text { between variables, metrics and indicators to deter- } \\
\text { mine how changes could produce overall system } \\
\text { change over time. It is important to have an accurate } \\
\text { conceptual model (e.g. a cause and effect diagram) } \\
\text { from the onset; then an appropriate modelling } \\
\text { software package is used to represent it. This } \\
\text { cause-effect conceptualization is the basis of many } \\
\text { other simulation packages. Usually used to simulate } \\
\text { possible effects of policies. }\end{array}$ & $\begin{array}{l}\text { Strength: it can give both a global and local view } \\
\text { on socio-economic viability, especially when } \\
\text { model is generalized. } \\
\text { Weakness: it depends on the proper under- } \\
\text { standing of the cause-effect dynamics between } \\
\text { variables. }\end{array}$ & $\begin{array}{l}\text { (Barisa, Romag- } \\
\text { noli, Blumberga, \& } \\
\text { Blumberga, 2015; } \\
\text { Musango, Brent, } \\
\text { Amigun, Pretorius, \& } \\
\text { Hans, 2012; Musan- } \\
\text { go, Brent, Amigun, } \\
\text { Pretorius, \& Müller, } \\
\text { 2011) }\end{array}$ \\
\hline $\begin{array}{l}\text { Feasibility assess- } \\
\text { ments/ } \\
\text { Enquiries } \\
\text { Quantitative and } \\
\text { qualitative approaches }\end{array}$ & $\begin{array}{l}\text { These are preliminary surveys made to establish } \\
\text { facts about the availability of adequate biomass, } \\
\text { financial and people resources or skills to support } \\
\text { a bioenergy venture. They could also look into the } \\
\text { policy landscape, potential supply chain partners, } \\
\text { markets and growth opportunities. Such a study is in } \\
\text { a strict sense, classified as qualitative since it thrives } \\
\text { on facts (statistical and non-statistical); unless } \\
\text { models are employed. }\end{array}$ & $\begin{array}{l}\text { Strengths: they give the first impression about } \\
\text { the feasibility of having a bioenergy project. } \\
\text { Such information is pertinent as it forms the } \\
\text { basis for other detailed studies. } \\
\text { Weaknesses: depending on approach, they may } \\
\text { require intensive field surveys and accurate data } \\
\text { acquisition methods, which can be difficult. } \\
\text { Accessibility and availability of information also } \\
\text { varies with country/region. }\end{array}$ & $\begin{array}{l}\text { (lakovou et al., } \\
\text { 2010; Skoulou \& } \\
\text { Zabaniotou, 2007; } \\
\text { Zhan, Chen, Noon, \& } \\
\text { Wu, 2005) } \\
\text { Global organiza- } \\
\text { tional studies on } \\
\text { biomass potential } \\
\text { e.g. by FAO and EU, } \\
\text { e.g. (Parikka, 2004), } \\
\text { (Ericsson \& Nilsson, } \\
\text { 2006) }\end{array}$ \\
\hline $\begin{array}{l}\text { Acceptability surveys } \\
\text { Largely qualitative } \\
\text { approach }\end{array}$ & $\begin{array}{l}\text { These surveys are usually done when there are } \\
\text { ethical or acceptability issues in the region where the } \\
\text { bioenergy project is targeted. In this case, a Public } \\
\text { Consultation and Communication (PC\&C) scheme } \\
\text { can be carried out. These studies are usually inte- } \\
\text { grated with other viability assessments. }\end{array}$ & $\begin{array}{l}\text { Strength: they have a good social thrust and } \\
\text { when recommendations are applied, they obtain } \\
\text { support from surrounding communities. } \\
\text { Weaknesses: alone, they are limited- they do } \\
\text { not give a bigger picture around the bioenergy } \\
\text { project (economic and environmental issues). }\end{array}$ & $\begin{array}{l}\text { (Nogueira et al., } \\
2017 \text { ) }\end{array}$ \\
\hline
\end{tabular}


et al. (2015) used SD to simulate the potential effect of bioenergy production on ecosystem dynamics such as biomass production, carbon capture and nitrogen utilization in the soil (Martinez-Hernandez, Leach, \& Yang, 2015). Cruz et al. (2009) applied the SD framework and developed a novel multi-time $\mathrm{I}-\mathrm{O}$ based modeling framework that can be used to simulate bioenergy supply chain dynamics (Cruz, Tan, Culaba, \& Ballacillo, 2009). Shastri et al. (2011) come up with an Agent Based Model using the theory of complex adaptive systems to simulate the system dynamics around agricultural biomass production, with farmers and the bio refinery as the 2 main independent agents (Y. Shastri, Rodríguez, Hansen, \& Ting, 2011). The likely decisions and interactions of each agent are modeled/predicted using a set of socio-economic and personalized attributes deemed to govern the agent's behavior. They use the model to simulate the production of Miscanthus in Illinois; it can however, only be accurate to the extent at which the attributes and interrelationships between agents in the system are correctly modeled. For instance, the attributes and responses of farmers, while they can be market driven, can also be subject to their attitudes- a difficult attribute to model. Such a model is, however, useful in obtaining a near/approximate projection of likely outcomes a few years down the line (Y. Shastri et al., 2011).

lakovou et al. (2010) claim that the majority of literature findings on the evaluation of biomass potential, selection of collection sites and capacity \& location of conversion facilities take a feasibility study inclination (lakovou et al., 2010). Shi et al. (2008) look into the feasibility/suitability of establishing new bio-power plants and optimizing their location using spatial information technologies like GIS and remote sensing; while Zhan et al. (2005) conduct a study to determine the economic feasibility of locating a switch grass-to-ethanol conversion plant in Alabama (Shi et al., 2008; Zhan et al., 2005). Both studies, though looking at feasibility, are very systematic since they use mathematical models and software solvers to assess the suitability/ feasibility of potential biomass sites that with available and usable biomass. They also use GIS to find optimal plant location based on the spatial distribution of usable biomass.

Qualitative viability assessments come in the form of feasibility and acceptability studies. Most feasibility studies that only seek to locate and quantify available, usable and non-usable biomass fall in this category and they are usually the interest of global humanitarian organizations. For instance, the Food and Agricultural Organization and regional organizations like the European Commission have undertaken global, regional and country specific surveys to quantify biomass in defined geographical spaces(Ericsson \& Nilsson, 2006; Parikka, 2004). Such studies already give the biomass potential of various regions, although some literature goes further to quantify biomass availability in smaller regions (lakovou et al., 2010).

\section{Integrated viability assessments}

Viability assessments are often integrated with optimization techniques and to span a part or the whole supply chain. Shastri et al. (2013) incorporate informatics, modeling and analysis and a decision support for biomass feed-
ConSEnT (Concurrent Science, Engineering \& Technology) Platform for Biomass Feedstock Production

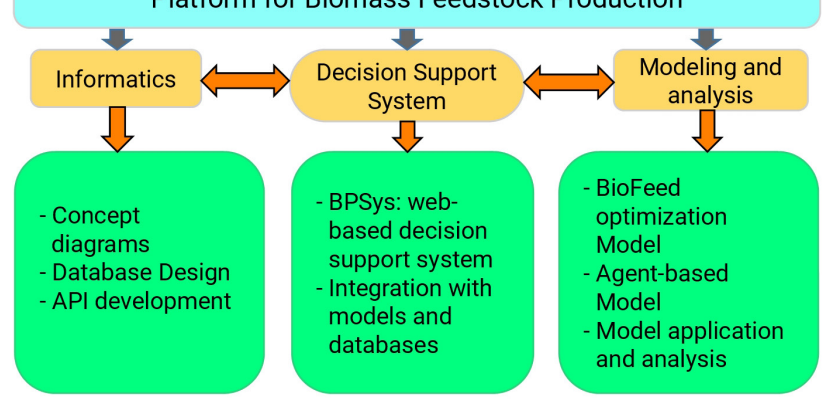

FIGURE 3: The ConSEnT integrated model for management of bio feed stocks (Y. Shastri, Hansen, Rodriguez, \& Ting, 2013).

stock production system in their integrated Concurrent Science, Engineering and Technology (ConSEnT) platform (Figure 3). This system then supports a regional bioenergy system, ensuring continuous operation of conversion facilities (Y. Shastri, Hansen, Rodriguez, \& Ting, 2013). The model does not connect with the Midstream processing facilities, therefore could be more appropriately termed a semi-integrated study, since it does not cover the full SC.

\subsubsection{Ascertaining viability through optimization}

The other set of viability studies try to ensure sustainability ahead of the bioenergy project through optimal use of resources. Whereas the viability assessments mostly inform policy makers or decision makers on viability issues at the macro socio-economic scale (spanning whole nations and regions), optimization techniques are usually project-centric and largely site specific. These optimization models are more at home in the viability rather than impact study category, with a goal to achieve the most sustainable/viable strategic, tactical or operational point. The optimal region in this case is always bound by the constraints introduced around the objective function- a mathematical model that represents pertinent social, economic and environmental goals. Inevitably, all optimization problems, by strict definition, follow the quantitative and systematic approach comprising objectives, constraints, a mathematical model and a software solver.

A number of authors concur that the two major constraints that hamper widespread uptake and dissemination of bioenergy projects: cost (a function of technical complexities, especially in the conversion technology) and the feedstock supply chain (SC) dynamics (Amundson et al., 2015; Batidzirai et al., 2012)(Ba et al., 2016). IRENA goes on to state that, for the advanced biofuel industry to be competitive compared to the fossil fuels, there is need for greater innovation in conversion technologies and supply chain models; market development and policy support (IRENA, 2016). Even where feed stocks are cheap, as in the case of forest residues (up to $50 \%$ cheaper than $1 \mathrm{G}$ feed stocks), the total cost for the feedstock supply significantly contributes towards high production costs; ranging from $40-70 \%$ (IRENA, 2016; Ji \& Long, 2016). This is due to the low energy density of biomass compared to fossil fuels, making it imperative to optimize supply chain logistics and minimize 
costs (Amundson et al., 2015; lakovou et al., 2010). Such a low energy density makes handling, storage and transportation of a unit of energy more expensive. Essentially, the complexities associated with the design and planning of biomass SCs emanate from the associated high costs of handling per unit energy, seasonal and uncertain nature of some feedstock supplies, variability of feedstock locations and other factors (lakovou et al., 2010). These and other reasons make for a strong case in optimizing these SCs, with various objectives such as minimizing costs, maximizing conversion throughput, minimizing $\mathrm{GHG}$ emissions and maximizing social returns, e.g. employment.

Despite an equally compelling case for research around feedstock supply chain dynamics and costs, most research has focused on the conversion technologies (Paolucci, Bezzo, \& Tugnoli, 2016). Recently, however, there has been an upward trend in research around biomass supply chains, though the initial bias was on assessment of potential biomass, allocation of collection sites and location of production facilities (lakovou et al., 2010). However, SC optimization is increasingly spanning a broader scope thanks to recent advances in computational tools, subsequent improvements in mathematical models and the recent realization that SC logistics are a major bottleneck in most bioenergy projects (Ba et al., 2016; Hadidi \& Omer, 2017; Pantaleo \& Shah, 2013). Still, more research is required to ascertain bioenergy projects viability through SC optimization to contribute to a significant reduction in the cost of the integrated bioenergy system (Gold \& Seuring, 2011; Hombach, Cambero, Sowlati, \& Walther, 2016; lakovou et al., 2010).

SC optimization literature generally concurs that supply chain complexities have to be addressed at 3 decision levels: strategic, tactical and operational (De Meyer, Cattrysse, Rasinmäki, \& Van Orshoven, 2014; lakovou et al., 2010), (Awudu \& Zhang, 2012). These are defined in Table 2, along with the activities normally tagged along these levels.

The other important consideration in the SC optimization studies is the part of the supply chain they focus on, since in principle, the entire supply chain comprises the production, harvesting or collection of biomass; transportation; pretreatment; storage; subsequent conversion to bioenergy (heat, power or fuels) and supply to markets. Figure 4 shows a classic biomass supply chain divided into:

- the upstream process that delivers the biomass in the appropriate form to the conversion facility;

- the midstream conversion process;

- then, finally, the downstream SC which concerns the supply and distribution of the bio-product (heat, power or fuels) to the market.

A number of studies look into SC optimization at the different levels shown in Table 2. For the strategic level, most of the researches take a multicriteria decision analysis (MCDA) approach based on many hierarchical attributes or objectives, often conflicting, which are analyzed mathematically to obtain an optimal choice (De Meyer et al., 2014). lakovou et al. (2010) analyze a synthesis of recent literature around the design and management of waste biomass supply chains (lakovou et al., 2010). They do not focus only on optimization models, but on the design and management of, specifically, waste biomass supply chains (WBSCs). This article starts off at a strategic decision- sourcing of the biomass- with a number of researchers using geographical bibliographies like those already published by humanitarian organizations (Skoulou \& Zabaniotou, 2007), and Geographical Information System (GIS) tools (Kinoshita, Inoue, Iwao, Kagemoto, \& Yamagata, 2009; Voivontas, Assimacopoulos, \& Koukios, 2001; Zhan et al., 2005). Of particular interest at the sourcing level are studies that try to minimize the costs of the supply chain by using a mix of biomass. Most of the studies are quantitative and systematic, using simulation and optimization models to compare options and combinations (Freppaz, Minciardi, Robba, \& Rovatti, 2004; Frombo, Minciardi, Robba, Rosso, \& Sacile, 2009).

A number of researchers look into the strategic capacity and location of conversion facilities; with some preferring to use GIS - based optimization. Panichelli and Gnansounou (2008) develop a methodology that integrates a GIS system with a biomass allocation algorithm to select suitable bioenergy facilities (Panichelli \& Gnansounou, 2008). Papadopoulos and Katsigiannis (2002) develop a GIS tool to locate a conversion facility considering economic sustainability (Papadopoulos \& Katsigiannis, 2002). Other facility location problems are solved use integer programming (IP); for instance Tembo et al. (2018) develop an mixed integer programming model to select the most economic biomass source and optimal bioethanol conversion facility location that maximizes net present profit (Tembo et al., 2018). Mixed Integer Linear Programming (MILP) is

TABLE 2: SC decision levels.

\begin{tabular}{|c|c|c|c|}
\hline Description & $\begin{array}{l}\text { Long term and usually invest- } \\
\text { ment intensive decisions that can } \\
\text { be revised after several years }\end{array}$ & $\begin{array}{l}\text { Address medium term decisions } \\
\text { (usually between } 6 \text { months to } 1 \\
\text { year) using guidelines provided } \\
\text { by strategic decisions }\end{array}$ & $\begin{array}{l}\text { Address short term decisions } \\
\text { (weekly, daily and hourly) }\end{array}$ \\
\hline Decision spheres and variables & $\begin{array}{l}\text { Conversion facilities- size and } \\
\text { technology to be used; biomass } \\
\text { supply network design \& config- } \\
\text { uration; facility location; sourcing } \\
\text { and procurement (including } \\
\text { supply contracts); }\end{array}$ & $\begin{array}{l}\text { Inventory planning \& control: } \\
\text { How much to harvest/collect and } \\
\text { store; selection, timing and place } \\
\text { of treatment technology. } \\
\text { Fleet management: transport } \\
\text { mode, shipment size, routing \& } \\
\text { scheduling, outsourcing options. }\end{array}$ & $\begin{array}{l}\text { Inventory planning \& control: Daily } \\
\text { inventory control and planning. } \\
\text { Fleet management: vehicle plan- } \\
\text { ning and scheduling }\end{array}$ \\
\hline Literature & $\begin{array}{l}\text { (De Meyer et al., 2014; lakovou et } \\
\text { al., 2010), (Tembo et al., 2018) }\end{array}$ & $\begin{array}{l}\text { (De Meyer et al., 2014; lakovou et } \\
\text { al., 2010), (Awudu \& Zhang, 2012) }\end{array}$ & $\begin{array}{l}\text { (De Meyer et al., 2014; lakovou et } \\
\text { al., 2010), (Awudu \& Zhang, 2012) }\end{array}$ \\
\hline
\end{tabular}




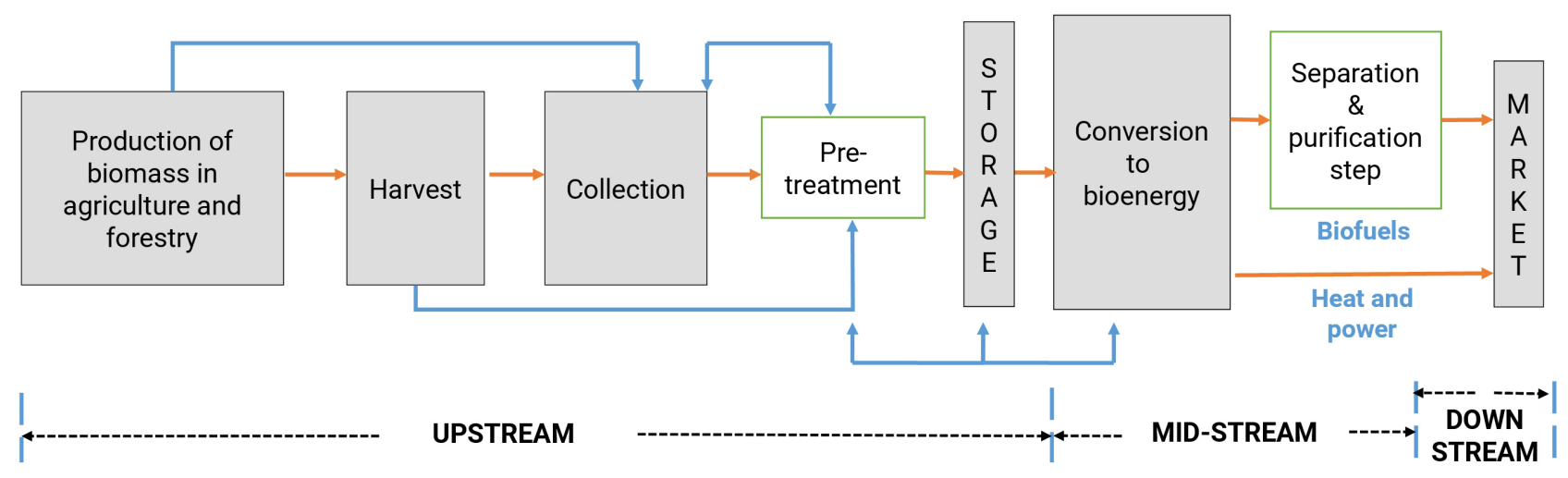

FIGURE 4: Biomass supply chain operations- Interrelationships and interdependencies. Arrows represent possible transport links (De Meyer et al., 2014).

used by many researchers at the strategic level spanning facility location and network design. Frequently, the MILP is embedded or combined with GIS, especially in facility location problems where a specific set of spatial criteria with respect to major highways, railroads or similar facilities are being considered. MILP tends to limit the researcher to one objective (usually the economic); whereas the common occurrence is that economic, ecological, energetic and social factors simultaneously affects supply chain decisions (De Meyer et al., 2014). Several authors therefore employ Pareto optimization to determine optimal Pareto trade off alternatives between various MILP objectives. Examples of researchers that have employed MILP only or along with GIS or Pareto for this purpose are summarized in Table 3.

Frombo et al. (2009) present an Environmental Decision Support System that optimizes the plant capacity and quantity of material harvested from a particular location, assuming a fixed plant location (Frombo et al., 2009).

A number of researchers combine strategic objectives with tactical; for instance network design or facility location (strategic) with fleet management or inventory planning (tactical) (Awudu \& Zhang, 2012; Gold \& Seuring, 2011; lakovou et al., 2010). Paolucci et al. (2016) present a two tier approach for the optimal SC configuration by considering the environmental and economic aspects (Paolucci et al., 2016). Tier 1 uses simplified assumptions and average, limited geographical information; giving a streamlined multi-objective optimization of the studied system. It therefore sets up a firm basis for a more detailed optimization with Tier 2 using Multi-objective Mixed Integer Linear Program (MoMILP); involving both strategic (e.g. optical locations) and tactical objectives like transport flow optimization. A more informed basis for decision making results from Tier 2, generating a benchmark for further assessments (Paolucci et al., 2016). lakovou et al. (2010) also point out that pre-treatment is also a critical tactical level decision to be made: i.e. to determine whether it is more effective to pre-treat before or after transporting, before subsequent storage (lakovou et al., 2010). The biomass mix to be used also determines the intensity of the treatment schedule: fresh biomass will require more drying compared to biomass that has been left to dry for some time. On the other hand, biomass that was treated or grown in contaminated areas, with certain compounds that may later affect microbes or catalysis, will require a more rigorous treatment schedule. As such, the characterization of the different biomass types is good to ascertain their quality in terms of the presence of certain poisonous substances.

This review will not delve into operational level optimization publications. It is, however, worth noting that the day to day operations are better modeled closer to or during the running of the project, when the strategic and tactical objectives are clearly mapped.

Amongst computational, systemic methods that seek to ascertain viability are heuristic approaches. These look for satisfactory, but not always optimal solutions as in the case of optimization techniques, with the advantage of reduced runtimes. They usually find good application in complex problems characterized by high uncertainties requiring stochastic approaches or with many objectives or constraints. The most popularly used heuristics are population based, mainly genetic algorithms (GAs), Particle Swarm Optimization (PSO) and binary honey bee foraging (BHBF) (De Meyer et al., 2014). The modus operandi of these is evolving a population of solutions through a given number of iterations, then returning a solution subset of the populations evolved when the stop condition is fulfilled. It is observed that most literature that uses heuristics apply them to strategic level optimization problems. Authors like Celli et al. (2008), Rentizelas and Tatsiopoulos (2010) apply GA, a mimic of natural evolution, in facility location, type, sizing and biomass sourcing/allocation (Celli, Ghiani, Loddo, Pilo, \& Pani, 2008; Rentizelas \& Tatsiopoulos, 2010). According to De Meyer et al. (2014)its inherent advantages over other heuristics and optimization techniques is that it can handle multiple variables, both continuous and discrete (De Meyer et al., 2014). It therefore can optimize non-continuous, non-linear, and non- differential functions simultaneously; and it evaluates a large population, not a single point. PSO is also evolutionary, but based on the social flocking or swarming behavior of creatures like birds and fish; found effective in multidimensional optimization as espoused by Izquierdo, Minciardi, Montalvo, Robba, \& Tavera (2008). BHBF is similar to PSO, however it is based on the swarm behavior of honey bees (De Meyer et al., 2014). 
TABLE 3: MILP hybrid optimizations.

\begin{tabular}{|c|c|c|}
\hline Study & Optimization model(s) used & Literature \\
\hline $\begin{array}{l}\text { Biodiesel supply chains from biomass produced by small scale Brazilian } \\
\text { farmers }\end{array}$ & MILP & $\begin{array}{l}\text { (De Campos Cesar Leão RR, } \\
\text { Hamacher S, 2010) }\end{array}$ \\
\hline Production of methanol from wood gasification, Austria & MILP & $\begin{array}{l}\text { (Sylvain Leduc, Schwab, Dotzauer, } \\
\text { Schmid, \& Obersteiner, 2008) }\end{array}$ \\
\hline Ethanol production from lignocellulosic biomass, Sweden & MILP & (S Leduc et al., 2010) \\
\hline $\begin{array}{l}\text { Optimal material flows and subsequent plant production costs for } \\
\text { different demand scenarios and supply options. Also demonstrated } \\
\text { differences between direct flow and flow via storage. }\end{array}$ & MILP and GIS & $\begin{array}{l}\text { (Kanzian, Holzleitner, Stampfer, \& } \\
\text { Ashton, 2009) }\end{array}$ \\
\hline $\begin{array}{l}\text { Pareto optimization to determine optimal Pareto trade off alternatives } \\
\text { between various MILP objectives }\end{array}$ & MILP and Pareto & $\begin{array}{l}\text { Mele, Kostin, Guillén-Gosálbez, } \\
\text { \& Jiménez, 2011; Zamboni, Shah, } \\
\text { Bezzo, \& others, 2009) }\end{array}$ \\
\hline $\begin{array}{l}\text { Optimal technology selection, bio refinery location and biomass flow } \\
\text { according to a combination of objectives specified by user (e.g. maximize } \\
\text { overall profit, minimize overall cost, minimize energy use etc.) }\end{array}$ & $\begin{array}{l}\text { MILP model (Biocolo) combined with } \\
\text { goal programming techniques }\end{array}$ & (Mol, Annevelink, \& Dooren, 2010) \\
\hline
\end{tabular}

\subsubsection{Integrated viability studies through optimization}

Nogueira et al. (2017) propose that the evaluation of a bioenergy process in some locality should take an integrated approach that seeks to understand the interrelationships between environmental, economic, social and technological factors. They do acknowledge the complexity of such a model given the numerous direct and indirect factors involved, for each site, country or region (Nogueira et al., 2017). Such studies should span a large part or the whole supply chain: the upstream (Supply-to-conversion Chain), Midstream (conversion) and downstream (Market supply) as illustrated in Figure 4. It is evident however, that most SC optimization literature cover the upstream supply chain and rightly so, since the biomass supply can be a bottleneck if the dynamics at this stage are poorly managed. The Midstream has its own challenges, which mostly have to do with the choice of technology and optimizing technical parameters to enhance productivity/yield, reduce GHG emissions, increase efficiency and ultimately reduce the cost of producing a unit of biofuel. In many cases, the upstream SC has a significant bearing on the conversion process; while the choice of the conversion technology may in turn, also influence the nature of the upstream SC. This interdependence is explained by the points below:

1. For a given $2 \mathrm{G}$ conversion technology, there is a minimum supply threshold required for an economic biofuel production. The minimum required inputs of biomass for Lignocellulosic fermentation, Biomass to Liquid/ Fischer Tropsch (BTL/FT) and Syngas fermentation conversion technologies are 2,280; 1,520 and 290 odt/ day respectively (E4tech, 2009). This in turn affects the choice of biomass mix to be employed in order to meet the stipulated supply requirement. As the biomass feedstock increases, economies of scale may also lead to a reduction in cost of production, depending on the rate of increase in cost of obtaining the biomass.

2. If the conversion technology has already been picked, it will affect the choice of biomass and subsequent location of the conversion plant. For instance, lignocellulosic fermentation route does not have the luxury of accepting multiple feed stocks; therefore, to avoid technical complexities in cellulosic breakdown and fermen- tation, a uniform feedstock is ideal. In this case, the preferred feedstock is agricultural residues (IRENA, 2016), whose lignin fraction is smaller than woody biomass or forest residues, since this part cannot be broken down during the conversion process.

3. For a provided conversion technology, other considerations like the biomass feedstock type, quality and pretreatment requirements have to be taken seriously. For instance, if lignocellulosic fermentation is to be used, then the pretreatment formula should avoid the release of many inhibitory substances (Kennes, Abubackar, Diaz, Veiga, \& Kennes, 2016; Walker, 2012). On the other hand, the catalysts in the BTL/FT process are sensitive to other contaminants that could be in the feedstock, like sulphur compounds, HCN, NOx and tar. This means that feedstock like treated poles with some traces of sulphur or, tar are not good for this process. That becomes a constraint on the biomass eligibility or otherwise implies higher treatment costs, which should be compared with the cost of alternative, distant feed stocks (E4tech, 2009). For syngas fermentation, vegetative matter brings in the danger of hydrogen cyanide contamination that is toxic to the acetogenic micro-organisms. This imposes a constraint on supplies of vegetative parts of the forest residues (E4tech, 2009).

Evidently, the type of conversion technology under consideration would impose more constraints around the biomass type, quantity, quality and pretreatment techniques to be used. As such, more integrated approaches that factor in, especially the type of conversion process to be used would bring in a broader perspective on SC optimization. Such approaches are scarce in literature because they usually require the collaborative input of different technical fields. The upstream SC part usually involves computational, industrial engineering and OR techniques, whereas conversion technology aspect will require core chemical engineering fundamentals. As Ba et al. (2016) suppose, integrated approaches will therefore require collaborative efforts between experts in these implicated fields, unless, the individual appreciates all these fields (Ba et al., 2016). Evidently, depending on the emphasis/thrust of the SC model (upstream/input or output parameters) the conversion module can be technically light or intensive. 
The conversion module can also be technically intensive, comprising models that house rigorous mass balances and/or thermodynamic modules. For instance, Eason and Cremaschi (2014) describe a multi-objective, quantitative and systematic network flow system for an 'ideal' biofuel production process defined mainly around achieving low cost, a high energy recovery from feedstock and low carbon emissions (Eason \& Cremaschi, 2014). The 3 available feed stocks are switch grass, corn and rapeseed, to be treated using alternative conversion technologies: gasification, anaerobic digestion, ethanol fermentation and transesterification. The result is a bio feedstock-to-biofuel super structure (BBSS) model with 17 production paths and requisite mass balance compositional data (Eason \& Cremaschi, 2014). Aksoy et al. (2011) also conduct an integrated study that compares four biomass and sawmill waste utilization avenues defined by four bio refinery alternatives: BTL/FT through Circulating Fluidized Bed gasification, Simultaneous Saccharification and fermentation (SSF), Direct Spout Bed (DSB) of biomass with air and steam and direct combustion. They come up with a Decision Support system (DSS) that combines SC optimization with economic feasibility analysis, spanning the upstream, midstream and downstream sections of the SC. They also use the I-O models to evaluate the potential impact of these various avenues (Aksoy et al., 2011). Another case of integration is solved by Leduc et al. (2008) who look into optimal location for the polygeneration of ethanol, heat and power. However, they use a readily available steady state simulation model for a polygeneration plant for ethanol, heat and power, then use it to generate input data into the optimization model that covers the rest of the supply chain (Sylvain Leduc et al., 2008).

Evidently, such integrated modules that feature intensive conversion modules make the integrated module complex, with large computational times; however, they do give a holistic picture that factors in a lot of detail. Ultimately, there has to be a good trade-off between the research and economic value of the model's results and the time, effort and resources used to obtain them.

\section{SOCIO-ECONOMIC IMPACT STUDIES}

Impact studies using various indicators and approaches have been used at national, regional and international levels. The relevant studies to be considered in this scope are national and regional studies that are associated with specific biofuel projects. Most impact studies use isolated methods for a qualitative analysis of indicators that reflect on the socio-economic effects of such a system (Nogueira et al., 2017). There has also been a call for more integrated impact study approaches that can give a holistic overview of socio-economic and ecological factors (Amundson et al., 2015; Leimbach et al., 2011).

\subsection{Isolated approaches}

Macro-economic studies usually have a double pronged purpose: to evaluate the up-to-date socio-economic impact of the project in question, then to project its effects on a nation or region's economic growth. They can also use impact evaluations from other geographically or socio-economically similar nations or regions to project the likely effects on the particular country or region of study (Nogueira et al., 2017). Macro-economic studies have been carried out in Southern African countries like Tanzania and Mozambique and indicated that biofuel expansion could fuel their economic growth (Gasparatos et al., 2015). The study in Mozambique particularly took the form of a General Equilibrium Model (GEM) which concluded that biofuel production could contribute $0.37 \%$ of its Gross Domestic Product (GDP) and generate 271,000 rural jobs (Gasparatos et al., 2015). Bento et al. (2014) used an 'inter-regional, bottom-up, dynamic GEM' embedded with the 2005 Brazilian Input-Output (I-O) table to evaluate the effects of increased ethanol production and indirect land use change (ILUC) (Bento, Ferreira, \& Horridge, 2014). In this approach, agriculture and land use were modeled separately for various regions and agricultural mixes.

I-O analyses are also widely used alone to assess macroeconomic impacts of bioenergy projects. They can be used to evaluate the impacts of new projects using $\mathrm{I}-\mathrm{O}$ tables that show annual monetary flow of goods and services among various economic sectors. The interdependence between these flows is noted, especially with regards to the addition of a new major bioenergy project to the economy. A number of authors have used this approach: Martinez et al (2013). used an I-O model to demonstrate significant socio-economic impacts of expanding sugarcane ethanol bio-projects in North-east Brazil (Herreras Martínez et al., 2013). Kunimitsu et al. (2013) used an inter-regional I-O analysis to evaluate the economic ripple effects of bioethanol production on countries within the Association of Southeast Asian Nations (ASEAN) (Kunimitsu, Takahashi, Furubayashi, \& Nakata, 2013). Evidently, the majority of hybrid approaches for impact studies have featured I-O analyses. For instance, You et al. looked into the optimum design of cellulosic biofuel SCs using multi-objective optimization (with socio-economic and ecological sustainability objectives) coupled with I-O analysis and LCA (You, Graziano, \& Snyder, 2012). This approach has both a viability assessment and impact assessment dimension, although the latter is projected using known historical facts/experiences. Souza et al. (2016) integrated Social Life Cycle Assessment (s-LCA) with I-O tables to develop quantitative social and environmental metrics to evaluate various ethanol production technologies in Brazil using impact assessment (Souza, Watanabe, Cavalett, Ugaya, \& Bonomi, 2016).

As with other impact studies, these macroeconomic studies depend on the accuracy of the facts tendered; for instance, the earlier macro-economic and life cycle assessment (LCA) studies made in Southern Africa on Jatropha could have misleading since they were based on inflated Jatropha yield statistics (Econergy, 2008; Gasparatos et al., 2015). Consequently, they reflected high developmental returns from such projects, which later proved inaccurate. Later reviews then suggested that the academics should have been gone on the ground to obtain comprehensive information rather than depend on reports (Gasparatos et al., 2015). This really brings an important aspect about impact studies, especially for such new proj- 
ects; scholars should not naively accept all the information from project proprietors, who at times, are desperate to prove that their models are perfect. They should endeavor to do proper historical research and not be content with desktop studies.

LCA assessments are studies (using dedicated software) used to quantify and compare ecological and energy flows associated with agricultural and manufacturing or processing stages in a product value chain, in most occasions, including transportation (Sobrino, Monroy, \& Pérez, 2011). Pradhan et al. (2014) comment on the fact that LCAs for biofuel projects are geographically specific. Consequently, a wide range of LCAs for somehow similar biofuel projects have yielded varying results due to differences in feedstock selection and types, conversion technology and system boundaries (Pradhan \& Mbohwa, 2014). Pradhan et al. (2014) then assert that localized LCA studies could therefore help select the right feedstock and technologies best suited to the nation(s) and advise policy makers accordingly (Pradhan \& Mbohwa, 2014). Generally, LCAs and their associated inventories ( $\mathrm{LCls}$ ) are static models that do not consider socio-economic mechanisms like maximization of profit. However, the Consequential Life Cycle Assessment (C-LCA) can model socio-economic mechanisms through market factors of general and partial equilibrium, such that the relationships between activities and processes are not static connections but dynamic entities (Nogueira et al., 2017). Marvuglia et al. (2013) modeled such a C-LCA for biogas production in Luxembourg, with an emphasis on indirect land use change (ILUC) (Marvuglia, Benetto, Rege, \& Jury, 2013).

\subsection{Integrated impact study approaches}

The majority of work done around evaluation of biofuel project impacts is based on isolated sections of the systems. Nogueira et al. (2017) bemoan the paucity of integrated, systematic methodologies for the comparison of the sustainability of various biofuel production systems (Nogueira et al., 2017). Indeed, such an integrated approach would give a holistic conclusion on the optimal parameters across the whole supply chain; however it is usually very complex, involving vast amounts of data and constraints, intricately constructed objectives and subsequently, complicated mathematical models and large computational times. These are the major drawbacks of an integrated approach either prior to the project or in retrospect; explaining why not so many scholars have used this route. However, it has been a growing area of interest in recent years. Nogueira et al. (2017) defines Integrated Assessment (IA) as a 'reflective and iterative participatory process that links knowledge (science) and action (policy) regarding complex global change issues such as bioenergy production and climate change' (Nogueira et al., 2017). Such an approach can be quantitative and systematic or qualitative. Leimbach et al. (2011) note that IA has grown popular as a tool for assessing strategies and policies around climate change; they assess the suitability of biofuel implementation strategies in the light of a complex ecological, and socio-economic matrix (Leimbach et al., 2011). However, literature reports that a few scholars use the IA approach in bioenergy production; one notable example being the systemic, 'SIByl-LACAf1 framework' proposed by Noguiera et al. (2017). It is presented as a sustainable, integrated approach where complementary evaluation methods are set in a logical and sequential array to assess the project's impact, along with a Strength, Weaknesses, Opportunities and Threats (SWOT) matrix (Nogueira et al., 2017). The mix of methods to be integrated can differ from project to project. Though largely a comprehensive approach due to the fact that it harnesses a pool of indicators derived from each method to give a holistic view, SIByl-LACAfl's robustness will always be subjective, depending on the individual suitability of the integrated methods selected, the logic used to arrange them sequentially and the method used to interpret the set of results obtained.

\section{CONCLUSIONS}

It is important to note that, though efforts have been made to distinguish between quantitative and systematic versus qualitative studies and viability assessments versus impact studies, there are occasional overlaps. For instance, some socio-economic impact case studies have been done and used as feedstock for viability studies in the same or similar regions (Pradhan \& Mbohwa, 2014),(Bamière, 2013),(S Leduc et al., 2010). Similarly, some quantitative and systematic studies have featured qualitative methods like case studies as support for certain projects; while it is also not unusual to find qualitative studies featuring some small quantitative and systematic models, especially from a statistical angle. It is also not rare, as some studies have revealed, to have a mix of approaches for a more comprehensive, integrated outcome. All the same, classifying the socio-economic studies and characterizing them gives a better perspective into the broad subject. Consequently, any research entity that will desire to carry out a socio-economic study should be able to clearly define their objectives and strategy, guided by the taxonomy provided in this review.

\section{REFERENCES}

Aksoy, B., Cullinan, H., Webster, D., Gue, K., Sukumaran, S., Eden, M., \& Sammons, N. (2011). Woody Biomass and Mill Waste Utilization Opportunities in Alabama : Transportation Cost Minimization, Optimum Facility Location, Economic Feasibility, and Impact, 30(4). https://doi.org/10.1002/ep .10501

Amundson, J., Sukumara, S., Seay, J., \& Badurdeen, F. (2015). Decision Support Models for Integrated Design of Bioenergy Supply Chains. Handbook of Bioenergy. https://doi.org/10.1007/978-3319-20092-7_7

Awudu, I., \& Zhang, J. (2012). Uncertainties and sustainability concepts in biofuel supply chain management: A review. Renewable and Sustainable Energy Reviews, 16(2), 1359-1368. https://doi. org/10.1016/j.rser.2011.10.016

Ba, B. H., Prins, C., \& Prodhon, C. (2016). Models for optimization and performance evaluation of biomass supply chains: An Operations Research perspective. Renewable Energy, 87, 977-989. https:// doi.org/10.1016/j.renene.2015.07.045

Badger, P., Badger, S., Puettmann, M., Steele, P., \& Cooper, J. (2011) Techno-Economic Analysis: Prelimiary Assessment of Pyrolysis Oil Production Costs and Material Energy Balance Associated with a Transportable Fast Pyrolysis System. BioResources, 6, 34-47.

Bamière, L. (2013). JOINT RESEARCH UNIT IN Stochastic viability of second generation biofuel chains : Micro-economic spatial modeling in France, 33(0), 0-21. 
Barisa, A., Romagnoli, F., Blumberga, A., \& Blumberga, D. (2015). Future biodiesel policy designs and consumption patterns in Latvia: a system dynamics model. Journal of Cleaner Production, 88, 7182. https://doi.org/10.1016/j.jclepro.2014.05.067

Batidzirai, B., Smeets, E. M. W., \& Faaij, A. P. C. (2012). Bioenergy for Sustainable Development in Africa, 117-130. https://doi. org/10.1007/978-94-007-2181-4

Bento, J., Ferreira, D. S., \& Horridge, M. (2014). Land Use Policy Ethanol expansion and indirect land use change in Brazil. Land Use Policy, 36, 595-604. https://doi.org/10.1016/j.landusepol.2013.10.015

Celli, G., Ghiani, E., Loddo, M., Pilo, F., \& Pani, S. (2008). Optimal location of biogas and biomass generation plants. Proceedings of the Universities Power Engineering Conference. https://doi.org/10.1109/ UPEC.2008.4651490

Cruz, J. B., Tan, R. R., Culaba, A. B., \& Ballacillo, J. A. (2009). A dynamic input-output model for nascent bioenergy supply chains. Applied Energy. https://doi.org/10.1016/j.apenergy.2009.04.007

Dassanayake, G. D. M., \& Kumar, A. (2012). Techno-economic assessment of triticale straw for power generation. Applied Energy, 98, 236-245. https://doi.org/10.1016/j.apenergy.2012.03.030

De Campos Cesar Leão RR, Hamacher S, O. (2010). Optimization of Biodiesel Supply Chains Based on Small Farmers: a case study in Brazil. Bioresource Technology.

De Meyer, A., Cattrysse, D., Rasinmäki, J., \& Van Orshoven, J. (2014). Methods to optimise the design and management of biomass-for-bioenergy supply chains: A review. Renewable and Sustainable Energy Reviews, 31, 657-670. https://doi.org/10.1016/j. rser.2013.12.036

Deenanath, E. D., lyuke, S., \& Rumbold, K. (2012). The bioethanol industry in sub-Saharan Africa: History, challenges, and prospects. Journal of Biomedicine and Biotechnology, 2012. https://doi. org/10.1155/2012/416491

E4tech. (2009). Review of Technologies for Gasification of Biomass and Wastes Final report. Retrieved from www.e4tech.com/wp-content/uploads/2016/01/gasification2009.pdf\%0A

Eason, J. P., \& Cremaschi, S. (2014). A multi-objective superstructure optimization approach to biofeedstocks-to-biofuels systems design. Biomass and Bioenergy, 63, 64-75. https://doi.org/10.1016/j. biombioe.2014.02.010

Econergy. (2008). Mozambique Biofuels Assessment. Ministry of Energy of Mozambique, 511. Retrieved from http://scholar.google. com/scholar?hl=en\&btnG=Search\&q=intitle:Mozambique+Biofuels+Assessment\#0

Ericsson, K. Ã., \& Nilsson, L. J. (2006). Assessment of the potential biomass supply in Europe using a resource-focused approach. Biomass and Bioenergy, 30, 1-15. https://doi.org/10.1016/j.biombioe.2005.09.001

Freppaz, D., Minciardi, R., Robba, M., \& Rovatti, M. (2004). Optimizing forest biomass exploitation for energy supply at a regional level, 26, 15-25. https://doi.org/10.1016/S0961-9534 (03)00079-5

Friends of the earth. (2009). Jatropha: Wonder crop? Retrieved from http://citeseerx.ist.psu.edu/viewdoc/download?doi=10.1.1.173.6 527\&rep=rep $1 \&$ type $=p d f$

Frombo, F., Minciardi, R., Robba, M., Rosso, F., \& Sacile, R. (2009). Planning woody biomass logistics for energy production: A strategic decision model. Biomass and Bioenergy, 33(3), 372-383. https:// doi.org/10.1016/j.biombioe.2008.09.008

Gasparatos, A., Von Maltitz, G. P., Johnson, F. X., Lee, L., Mathai, M., Puppim De Oliveira, J. A., \& Willis, K. J. (2015). Biofuels in sub-Sahara Africa: Drivers, impacts and priority policy areas. Renewable and Sustainable Energy Reviews, 45, 879-901. https://doi. org/10.1016/j.rser.2015.02.006

Gold, S., \& Seuring, S. (2011). Supply chain and logistics issues of bio-energy production. Journal of Cleaner Production, 19(1), 3242. https://doi.org/10.1016/j.jclepro.2010.08.009

Hadidi, L. A., \& Omer, M. M. (2017). A financial feasibility model of gasification and anaerobic digestion waste-to-energy (WTE) plants in Saudi Arabia. Waste Management, 59, 90-101. https://doi. org/10.1016/j.wasman.2016.09.030

Herreras Martínez, S., Van Eijck, J., Pereira Da Cunha, M., Guilhoto, J. J. M., Walter, A., \& Faaij, A. (2013). Analysis of socio-economic impacts of sustainable sugarcane-ethanol production by means of inter-regional Input-Output analysis: Demonstrated for Northeast Brazil. Renewable and Sustainable Energy Reviews. https://doi. org/10.1016/j.rser.2013.07.050
Hombach, L. E., Cambero, C., Sowlati, T., \& Walther, G. (2016). Optimal design of supply chains for second generation biofuels incorporating European biofuel regulations. Journal of Cleaner Production, 133, 565-575. https://doi.org/10.1016/j.jclepro.2016.05.107

lakovou, E., Karagiannidis, A., Vlachos, D., Toka, A., \& Malamakis, A. (2010). Waste biomass-to-energy supply chain management: A critical synthesis. Waste Management, 30(10), 1860-1870. https://doi.org/10.1016/j.wasman.2010.02.030

IRENA. (2016). Innovation Outlook Advanced Liquid Biofuels, 132. Retrieved from http://www.irena.org/DocumentDownloads/Publications/IRENA_Innovation_Outlook_Advanced_Liquid_Biofuels_2016.pdf

Izquierdo, J., Minciardi, R., Montalvo, I., Robba, M., \& Tavera, M. (2008) Particle Swarm Optimization for the biomass supply chain strategic planning. Proc. IEMSs 4th Biennial Meeting - Int. Congress on Environmental Modelling and Software: Integrating Sciences and Information Technology for Environmental Assessment and Decision Making, IEMSs 2008, 2, 1272-1280.

Ji, X., \& Long, X. (2016). A review of the ecological and socioeconomic effects of biofuel and energy policy recommendations, 61, 41-52. https://doi.org/10.1016/j.rser.2016.03.026

Kanzian, C., Holzleitner, F., Stampfer, K., \& Ashton, S. (2009). Regiona Energy Wood Logistics - Optimizing Local Fuel Supply, 43(December 2008).

Kinoshita, T., Inoue, K., Iwao, K., Kagemoto, H., \& Yamagata, Y. (2009). A spatial evaluation of forest biomass usage using GIS, 86, 1-8. https://doi.org/10.1016/j.apenergy.2008.03.017

Kunimitsu, Y., Takahashi, K., Furubayashi, T., \& Nakata, T. (2013). Economic ripple effects of bioethanol production in ASEAN countries: Application of inter-regional input-output analysis. Japan Agricultural Research Quarterly, 47(3), 307-317. https://doi.org/10.6090/ jarq.47.307

Leduc, S., Schwab, D., Dotzauer, E., Schmid, E., \& Obersteiner, M. (2008). Optimal location of wood gasification plants for methanol production with heat recovery, (March), 1080-1091. https://doi. org/10.1002/er

Leduc, S., Starfelt, F., Dotzauer, E., Kindermann, G., Mccallum, I., Obersteiner, M., \& Lundgren, J. (2010). Optimal location of lignocellulosic ethanol refineries with polygeneration in Sweden. EGY, 35(6), 2709-2716. https://doi.org/10.1016/j.energy.2009.07.018

Leimbach, M., Popp, A., Lotze-Campen, H., Bauer, N., Dietrich, J. P., \& Klein, D. (2011). 10 Integrated assessment models-the interplay of climate change, agriculture and land use in a policy tool. Handbook on Climate Change and Agriculture.

Martinez-Hernandez, Elias; Leach, Matthew; Yang, A. (2015). Impact of Bioenergy Production on Ecosystem Dynamics and Services-A Case Study on U.K. Heathlands.

Marvuglia, A., Benetto, E., Rege, S., \& Jury, C. (2013). Modelling approaches for consequential life-cycle assessment (C-LCA) of bioenergy: Critical review and proposed framework for biogas production. Renewable and Sustainable Energy Reviews. https://doi. org/10.1016/j.rser.2013.04.031

Mele, F. D., Kostin, A. M., Guillén-Gosálbez, G., \& Jiménez, L. (2011). Multi-objective Model for More Sustainable Fuel Supply Chains. Industrial \& Engineering Chemistry Research. https://doi. org/10.1021/ie101400g

Mol, R. M. De, Annevelink, E., \& Dooren, H. J. C. Van. (2010). Optimization of the logistics of agricultural biogas plants, (December).

Musango, J. K., Brent, A. C., Amigun, B., Pretorius, L., \& Hans, M. (2012). Technovation A system dynamics approach to technology sustainability assessment: The case of biodiesel developments in South Africa, 32, 639-651. https://doi.org/10.1016/j.technovation.2012.06.003

Musango, J. K., Brent, A. C., Amigun, B., Pretorius, L., \& Müller, H. (2011). Technology sustainability assessment of biodiesel development in South Africa: A system dynamics approach. Energy, 36(12), 6922-6940. https://doi.org/10.1016/j.energy.2011.09.028

Nogueira, L. A. H., Antonio de Souza, L. G., Cortez, L. A. B., \& Leal, M. R. L. V. (2017). Sustainable and Integrated Bioenergy Assessment for Latin America, Caribbean and Africa (SIByl-LACAf): The path from feasibility to acceptability. Renewable and Sustainable Energy Reviews, 76(March), 292-308. https://doi.org/10.1016/j. rser.2017.01.163

Panichelli, L., \& Gnansounou, E. A. (2008). GIS-based approach for defining bioenergy facilities location : A case study in Northern Spain based on marginal delivery costs and resources competition between facilities, 32, 289-300. https://doi.org/10.1016/j.biombioe.2007.10.008 
Pantaleo, A. M., \& Shah, N. (2013). The Logistics of Bioenergy Routes for Heat and Power. Biofuels - Economy, Environment and Sustainability, 217-244. https://doi.org/10.5772/50478

Paolucci, N., Bezzo, F., \& Tugnoli, A. (2016). A two-tier approach to the optimization of a biomass supply chain for pyrolysis processes. Biomass and Bioenergy, 84, 87-97. https://doi.org/10.1016/j. biombioe.2015.11.011

Papadopoulos, D. P., \& Katsigiannis, P. A. (2002). Biomass energy surveying and techno-economic assessment of suitable CHP system installations, 22, 105-124.

Parikka, M. (2004). Global biomass fuel resources. Biomass and Bioenergy, 27, 613-620. https://doi.org/10.1016/j.biombioe.2003.07. 005

Patel, M., Zhang, X., \& Kumar, A. (2016). Techno-economic and life cycle assessment on lignocellulosic biomass thermochemical conversion technologies: A review. Renewable and Sustainable Energy Reviews, 53, 1486-1489. https://doi.org/10.1016/j. rser.2015.09.070

Pradhan, A., \& Mbohwa, C. (2014). Development of biofuels in South Africa: Challenges and opportunities. Renewable and Sustainable Energy Reviews, 39, 1089-1100. https://doi.org/10.1016/j. rser.2014.07.131

Rentizelas, A. A., \& Tatsiopoulos, I. P. (2010). Locating a bioenergy facility using a hybrid optimization method. International Journal of Production Economics, 123(1), 196-209. https://doi. org/10.1016/j.ijpe.2009.08.013

Shastri, Y. ., Hansen, A. ., Rodriguez, L. ., \& Ting, K. (2013). Systems Informatics and Analysis of Biomass Feedstock Production. Pertanika Journal Science and Technology, 21(2), 273-279. Retrieved from http://www.pertanika.upm.edu.my/

Shastri, Y., Rodríguez, L., Hansen, A., \& Ting, K. C. (2011). Agent-Based Analysis of Biomass Feedstock Production Dynamics. Bioenergy Research, 4(4), 258-275. https://doi.org/10.1007/s12155-0119139-1

Shi, X., Elmore, A., Li, X., Gorence, N. J., Jin, H., Zhang, X., \& Wang, F. (2008). Using spatial information technologies to select sites for biomass power plants : A case study in Guangdong, 32, 35-43. https://doi.org/10.1016/j.biombioe.2007.06.008

Skoulou, V., \& Zabaniotou, A. Ã. (2007). Investigation of agricultural and animal wastes in Greece and their allocation to potential application for energy production \$, 11, 1698-1719. https://doi. org/10.1016/j.rser.2005.12.011

Sobrino, F. H., Monroy, C. R., \& Pérez, J. L. H. (2011). Biofuels and fossi fuels: Life Cycle Analysis (LCA) optimization through productive resources maximization. Renewable and Sustainable Energy Reviews. https://doi.org/10.1016/j.rser.2011.03.010

Souza, A., Watanabe, M. D. B., Cavalett, O., Ugaya, C. M. L., \& Bonomi, A. (2016). Social life cycle assessment of first and second-generation ethanol production technologies in Brazil. The International Journal of Life Cycle Assessment. https://doi.org/10.1007/ s11367-016-1112-y

Tembo, G., Epplin, F. M., Huhnke, R. L.,Tembo, G.,Epplin, F. M. \& Huhnke R. L. (2018). Integrative Investment Appraisal of a Lignocellulosic Biomass-to-Ethanol Industry Integrative Investment Appraisal of a Lignocellulosic Biomass-to-Ethanol Industry, 28(3), 611-633.

Timilsina, G. R., \& Shrestha, A. (2010). Biofuels Markets, Targets and Impacts. Retrieved from https://hub.globalccsinstitute.com/sites/ default/.../biofuels-markets-targets-impacts.pdf

Voivontas, D., Assimacopoulos, D., \& Koukios, E. G. (2001). Assessment of biomass potential for power production : a GIS based method, 20, 101-112.

Von Maltitz, G. P., \& Setzkorn, K. A. (2013). A typology of Southern African biofuel feedstock production projects. Biomass and Bioenergy, 59, 33-49. https://doi.org/10.1016/j.biombioe.2012.11.024

You, F., Graziano, D. J., \& Snyder, S. W. (2012). Optimal Design of Sustainable Cellulosic Biofuel Supply Chains: Multiobjective Optimization Coupled with Life Cycle Assessment and Input - Output Analysis. AIChE Journal. https://doi.org/10.1002/aic .12637

Zamboni, A., Shah, N., Bezzo, F., \& others. (2009). Spatially explicit static model for the strategic design of future bioethanol production systems. 1. Cost minimization. Energy \& Fuels.

Zhan, F. B., Chen, X., Noon, C. E., \& Wu, G. (2005). A GIS-enabled comparison of fixed and discriminatory pricing strategies for potential switchgrass-to-ethanol conversion facilities in Alabama, 28, 295306. https://doi.org/10.1016/j.biombioe.2004.06.006 